IRA-International Journal of Education \&

Multidisciplinary Studies

ISSN 2455-2526; Vol.16, Issue 02 (April-June, 2020)

Pg. no. 123-127.

Institute of Research Advances

https://research-advances.org/index.php/IJEMS

\title{
A Cognitive Study of the Color Metaphor of Yellow
}

Li Yan

School of Foreign Studies, Yangtze University, Jingzhou, Hubei, China.

Type of Work: Peer-Reviewed

DOl: http://dx.doi.org/10.21013/jems.v16.n2.p5

\section{How to cite this paper:}

Yan, Li. (2020). A Cognitive Study of the Color Metaphor of Yellow. IRA International Journal of Education and Multidisciplinary Studies (ISSN 2455-2526), 16(2), 123-127. DOI: http://dx.doi.org/10.21013/jems.v16.n2.p5

(C) Institute of Research Advances.

This work is licensed under a Creative Commons Attribution-NonCommercial 4.0 International License subject to a proper citation to the publication source of the work.

Disclaimer: The scholarly papers as reviewed and published by the Institute of Research Advances (IRA) are the views and opinions of their respective authors and are not the views or opinions of the IRA. The IRA disclaims of any harm or loss caused due to the published content to any party.

Institute of Research Advances is an institutional publisher member of Publishers International Linking Association Inc. (PILA-CrossRef), USA. The institute is an institutional signatory to the Budapest Open Access Initiative, Hungary advocating the open-access of scientific and scholarly knowledge. The Institute is a registered content provider under Open Access Initiative Protocol for Metadata Harvesting (OAI-PMH).

The journal is indexed \& included in WorldCat Discovery Service (USA), CrossRef Metadata Search (USA), WorldCat (USA), OCLC (USA), Open J-Gate (India), EZB (Germany) Scilit (Switzerland), Airiti (China), Bielefeld Academic Search Engine (BASE) of Bielefeld University, Germany, PKP Index of Simon Fraser University, Canada. 


\begin{abstract}
A metaphor is the substitution of unknown things by familiar or perceptible things. Traditional linguistic theory regards metaphor as a rhetorical device and metaphorical linguistic transformation as an inter-lingual transformation at the rhetorical level. Cognitive linguistic theory holds that metaphor is not only a linguistic phenomenon, but also an important cognitive way, which provides a new study of language cognition and transformation. From the perspective of cognitive linguistics, this paper analyses metaphorical phenomena and explores the transformation of metaphorical language to deepen readers' understanding of metaphorical language and broaden the scope of application of metaphorical techniques.
\end{abstract}

\title{
1. Cognitive linguistics
}

Cognitive linguistics is a linguistic school formed from the 1980s to the 1990s. Its foundation is cognitive science and cognitive philosophy, which is opposite to the "transformational generation" school. Artificial intelligence, linguistics, psychology, and systematics are all the research fields of cognitive linguistics. This school puts forward its viewpoint based on language generation. It holds that language learning and application can be realized through people's cognition. American linguists George Lakoff, Mark Johnson, and Ronald Langacker are the founders of cognitive linguistics. Lakoff and Johnson's main research content is the relationship between cognition and metaphor in human language. Langacker's main achievement is cognitive grammar. Lakoff proposes that metaphor is a cognitive ability that human beings must master and a linguistic paradigm. They generally believe that the experience accumulated in the daily use of language is the basis of applied language, and there is a close relationship between the human ability to interpret language and cognitive ability.

Cognitive linguistics holds that meaning and concept have the same effect. The process of language use is the process of forming a psychological experience structure. The meaning implied in language expression is the concept activated in the brain of the narrator or listener. Vocabulary and larger linguistic units are the entrance to the whole cognitive structure and knowledge network. If a comprehensive interpretation of an expression is needed, imagery (visual and non-visual), metaphor, mental model, and simple understanding of the world must be taken into account. Language expression is not only right or wrong but also acceptable. The process of accepting language is gradual. The most important and essential feature of cognitive linguistics is to explore linguistic phenomena in the process of cognition. This theory holds that syntax is customary and that sound or symbols are meaningful because they carry established concepts.

\section{Cognition and Metaphor of Language}

According to Lakoff and Johnson, the essence of metaphor is to realize the recognition of other things through the understanding of one thing, and it is a means to explain language phenomena by using cognitive theory. Metaphor originates in the process of thinking and can effectively reflect the process of people's understanding of the world. People's understanding of new things is often based on metaphor, which has been paid more and more attention by linguists because of its important role. In the study of metaphor based on cognitive theory, image schema and cognitive experience are the philosophical basis of metaphor theory. Image schema is a cognitive structure established based on people's cognition. It is a way solidified in the mind formed in the process of understanding abstract 
connections and concrete images, which directly determines people's cognitive structure. Lakoff and Johnson have studied metaphor from a philosophical point of view. This is an empirical epistemological view.

\section{Conceptual metaphor theory}

Conceptual metaphor theory is one of the most important theories in cognitive linguistics. Lakoff and Johnson formally put forward the concept of "conceptual metaphor" in their book Metaphor on which we live, published in 1980. According to this theory, metaphor is a matter of thinking, not of language expression. Therefore, conceptual metaphor is a matter of thinking, not of language expression. Their research shows that metaphor exists universally in our daily life, and our thoughts and actions. The general conceptual system on which we rely for thinking and action is fundamentally metaphorical. The essence of metaphor is to understand and experience one thing or experience another.

Conceptual metaphor is an important concept of Lakoff's metaphor theory, and it is also an important part of cognitive linguistics. Conceptual metaphor is different from what we usually call metaphor. It is a general summary of general metaphorical expressions. Its most striking characteristics are traditionality, systematicness, and abstract generality. For example, Life is a journey is a conceptual metaphor abstractly summarized from the remarkable features of life and debate in a large number of daily life and literary languages, which is the result of people's concretization of the abstract concept of "life". Therefore, it is not difficult to see that the conceptual metaphor is highly generalized. Conceptual metaphor can help us understand more clearly the abundant ways of metaphorical expression in our daily life.

\section{Metaphorical Analysis of the word Yellow}

\subsection{Yellow}

Conceptual metaphors related to the color word "yellow" in both English and Chinese are identical and different. The similarity is based on the commonness of human thinking, while the difference is rooted in cultural individuality and different ways of thinking. Therefore, the understanding of the metaphor of "yellow" in Chinese and English color words has to depend on their cultural background. When learning these color words, we should fully consider the social and cultural colors and emotional connotations contained in them and make a cultural comparison.

Symbol of sadness and death: Yellow is often associated with autumn. In both English and Chinese languages and cultures, it is a symbol of withering, decay, and sad death. Yellow can symbolize "death", "desolation" and "depression". These semantic components are mapped into people's cognitive system. When the autumn wind comes, the leaves turn yellow and the earth becomes desolate. Therefore, both East and West tend to associate yellow or yellow with "death", "desolation" and "depression". In Chinese, expressions such as "yellowface, thin muscles", "yellow flowers of tomorrow", "old pearls and yellow people", "a dream of yellow sorghum" and "things are yellow" all have the flavor of disease, decay and failure. For example, Li Qingzhao, a poet of the Song Dynasty in China, read "People are thinner than yellow flowers" to break her intestines. And the poet Lulun sighed in his sad autumn: "Spring goes white, autumn leaves yellow. Scratch your head to the yellow leaves and share your sorrow with you in autumn". In British and American cultures, yellow is also used to mean desolate death. In English, yellow blight (yellow blight), yellow fever (infectious diseases caused 
by tropical viruses), and yellow flag (symbols of epidemics on ships) all have negative associations of death. In the end, Macbeth in Shakespeare's works described his loneliness and sadness in his heart by saying that his "life is fallen into the sea"(the yellow leaf). In Ode to the West Wind, Shelley, a famous British Romantic poet, calls the yellow leaves "dead leaves", describing them as "monsters infected with the plague and blown away by the strong west wind".

Symbol of hint and warning: yellow in English phrases and yellow in Chinese both have the meaning of reminders and warnings, which are used to emphasize key points and emergencies. For example, in Chinese, "green and yellow do not connect" means that the old grain has been eaten, and the new grain is not yet ripe. Similarly, there are "seedling yellow lack of fertility, yellow people are sick", "facial yellow muscle thin", "jaundice hepatitis". "Yellow" also serves as a warning in Western culture. In Britain, the "yellow line" refers to the Yellow single or double lines drawn along the roadside, usually indicating parking restrictions. "Yellow warming card" originally refers to the Yellow card, which was widely used in sports competitions later, indicating that the referee warned the offenders and coaches. "Yellow flag" refers to the yellow flag on a quarantined ship, which is not allowed to be approached by ordinary people. "Yellow alert" means air raid preparedness alert. "Yellow cross" is the symbol of poison gas. "Yellow sheet" means a criminal record with a criminal record.

\subsection{Cultural conflicts and cognitive differences.}

Culture has its commonness as well as its individuality. Similarly, when projected into the cognitive system, the result is that the meaning expressed is different. Although the conceptual meaning of the same color word corresponds to that of the Chinese and English languages, its socio-cultural color and emotional connotation may differ greatly due to its different social and cultural backgrounds. Due to the differences between English and Chinese cultures, people's living environment, mental state and thinking mode are not identical. The complete equivalence and equivalence of vocabulary in different languages are limited and relative.

Yellow is regarded as a respectful color and has a long history in the Han culture. Therefore, except for the Son of Heaven, ordinary people dare not dye their fingers yellow. "Huangpao", "Huangbang", "Huangmen" and so on are closely linked with different honors and glories. The symbolic significance of the loftiness, dignity, and power of yellow occupies an extremely important position in Chinese psychology. In English, yellow means mean, cowardice, jealousy, and so on. In the Bible, it is said that Judas sold Jesus for 30 silver coins. Judas always wore yellow clothes, so yellow has metaphorical concepts of betrayal and evil in English. For example: They look yellow.

Yellow is often said to be a "spring chicken" in Chinese, while in English "yellow" can also be used to indicate age, but its metaphorical cognition is the opposite. For example, "sere and yellow" can be translated as "old age". In recent years, "yellow" can easily lead to "pornographic", "filthy", "obscene", "obscene" cognitive psychology, such as "anti-pornographic" and so on. And what we call "blue" and "yellow joke" in Chinese are translated into English as "blue movie" and "blue joke". However, the word yellow is used in the phrase "yellow journalism" in English. It refers to the Yellow news-editorial style that exaggerates and exaggerates by all means to attract or influence readers, such as highlighting social scandals, making ordinary news sensational, and sometimes even distorting facts to cause a sensation. In Chinese, there is no special color word for "yellow" to express this meaning. 


\section{Conclusion}

Yellow is only one aspect of color metaphor. The same color represents the same meaning in different languages, but there are also many differences. There are similarities and differences in the conceptual metaphor of color between the two languages, but there are also many personalities. It contains a great deal of cultural information, and the conceptual metaphorical meanings are different from each other both visually and psychologically. The purpose of analyzing the similarities and differences between them is to enhance the relationship between language culture and social culture, and to effectively carry out cross-cultural verbal communication, to improve the pragmatic competence of cross-cultural communication.

\section{References:}

[1]. Lakoff. G. and M. Johnson. Metaphors We Live by [M] Chicago; Chicago University Press, 1980.

[2]. Bao Huinan. Cultural Context and Language Translation [M]. Beijing: China Foreign Translation and Publishing Corporation, 2001.

[3]. Deng Yanchang. Language and Culture-Comparison of English and Chinese Language and Culture [M]. Beijing; Foreign Language Teaching and Research Press, 2006.

[4]. Li Fuyin. Introduction to Semantics (Revised Edition) [M]. Beijing; Peking University Press, 2006.

[5]. Li Fuyin. Introduction to Cognitive Linguistics [M]. Beijing; Peking University Press, 2008.

[6]. Liu Shili. Semantics: Meaning, Structure and Cognition [M]. Beijing; World Knowledge Press, 2006.

[7]. Peng Jilin. The English Translation Strategy of "Green" Words in Chinese [J]. Journal of Yunnan Normal University 2009,03.

[8]. Zhang Meijun. Cultural Cognitive Analysis of English and Chinese Yellow Conceptual Metaphors [J]. Journal of Mianyang Normal University, 2011.

[9]. Langacker R. Foundations of Cognitive Grammar[M].Vol1.Stanford: Stanford University Press, 1987.

[10].Rosch E. Natural categories[J].Cognitive Psychology,1973(4).

[11].Brent Berlin, Paul Kay. Basic Color Terms: Their University and Evolution[M].California: Berkeley University of California Press, 1969.

[12].Zhang Peiji. English Semantic Words and Translation [M]. Beijing: Commercial Press, 1964. 